\title{
Choosing the Best Oral Diabetic Agents in T2 Diabetes Mellitus- Physicians Challenge
}

\section{Bijaya Mohanty*}

Department of Medicine, Tata Main Hospital, Jamshedpur, India

*Corresponding author: Bijaya Mohanty, Consultant, Department of Medicine, Tata Main Hospital, Jamshedpur, India, Tel: +91-7763807140; E-mail: bijayamohantytmh@gmail.com

Received date: June 02, 2018; Accepted date: June 26, 2018; Published date: June 30, 2018

Copyright: (C) 2018 Mohanty B. This is an open-access article distributed under the terms of the Creative Commons Attribution License, which permits unrestricted use, distribution, and reproduction in any medium, provided the original author and source are credited.

\begin{abstract}
The therapeutic armamentarium of oral diabetic agents has expanded its horizon from sulfonylureas in 1995 the only drug available for treating type 2 diabetes mellitus at that time to eleven classes of oral diabetes agents at present ranging from biguanides, thiazolidinediones, dipeptidyl peptidase-4 (DPP-4) inhibitors, alpha glucosidase inhibitors and sodium-glucose cotransporter (SGLT2) inhibitors. Despite the availability of so many options glycemic control remains suboptimal posing a real challenge for the clinicians to choose the best amongst them in treating type 2 diabetes mellitus.

Before choosing the drugs it is important to know the recommendations of glycemic goals in adults. A reasonable glycosylated hemoglobin (A1C) goal in adult is $<7 \%$. However all glycemic goals should be individualized and customized. Setting individual glycemic goals needs consideration of several factors like risk of hypoglycemia and other adverse effects of drugs, disease duration, age and life expectancy of patients and other individual patient considerations like patients attitude resources and support system. Till today our approach towards diabetes management is GLUCOCENTRIC. The key component being how to achieve glycemic control with minimal side effects. While choosing drugs the factors considered are its efficacy (A1c reduction), risk of hypoglycaemia, effect on weight and other adverse effects, cost, ease of administration and patient's preference. A patient-centered approach is of paramount importance while choosing the pharmacological agents rather that establishing a universally accepted algorithm as this will definitely improve the compliance. The advantages and disadvantages of each class of agents help the practitioners to choose the best options.
\end{abstract}

Keywords: Diabetes mellitus; A1C; Oral diabetic drugs; Hypoglycemia

\section{Introduction}

Good glycemic control remains the cornerstone of managing T2 diabetes mellitus. Such approaches play a vital role in preventing or delaying the onset and progression of diabetic complications. The therapeutic armamentarium of oral diabetic agents has expanded its horizon from sulfonylureas in 1995 the only drug available for treating type 2 diabetes mellitus at that time to eleven classes of oral diabetes agents at present ranging from biguanides, thiazolidinediones, dipeptidyl peptidase-4 (DPP-4) inhibitors, meglitinides, glucagon-like receptor agonists, an amylin analogue, bromocriptine, bile-acid sequestrant, alpha glucosidase inhibitors and sodium-glucose cotransporter (SGLT2) inhibitors. Despite the availability of so many options it's a real challenge for the clinicians to choose the best amongst them in treating type 2 diabetes mellitus.

The pathophysiological mechanisms underlying T2 diabetes mellitus are reduced insulin secretion from pancreatic $\beta$-cells, elevated glucagon secretion from pancreatic a cells, increased hepatic glucose production, neurotransmitter dysfunction and insulin resistance, enhanced lipolysis, increased renal glucose reabsorption, reduced incretin effect in the small intestine, and impaired or diminished glucose uptake in peripheral tissues such as skeletal muscle, liver, and adipose tissue which occurs in isolation or in combination. Currently available glucose-lowering therapies target one or more of these key pathways.

\section{Setting a Target}

Good glycemic control is reflected by HBA1C which remains the foundation of managing T2 Diabetes Mellitus. Before choosing the drugs it is important to know the recommendations of glycemic goals in adults. A reasonable A1C goal in adult is $<7 \%$. However all glycemic goals should be individualized and customized. Setting individual glycemic goals needs consideration of several factors. The disease related factors are duration of diabetes, age and life expectancy of patients and associated comorbid conditions. The most important drug related factors are adverse effects of drugs specially risk of hypoglycemia. Patient's attitude, resources and support system also helps in deciding individual glycemic targets. More stringent goals $(<6.5 \%)$ are recommended in people with low risk of hypoglycemia, newly diagnosed cases, long life expectancy, absent co morbidities and vascular complications, patients who are highly motivated, adherent to therapy and with readily available resources and support system. On the other hand less stringent goals $(<8 \%)$ are targeted for patients with high risk of hypoglycemia, long standing disease, short life expectancy, associated co morbidities, vascular complications and those who are non-compliant or poor self-care capacity and limited resources. 


\section{Choice of Drugs}

While choosing oral diabetic drugs one must consider its efficacy, potential adverse effects, and effects on weight gain, risk of hypoglycemia, cardio protectiveness and cost of therapy. It is also important to have a patient centered approach to guide the choice of pharmacological agents. The major classes of oral antidiabetic medications include biguanides, sulfonylureas, meglitinides, thiazolidinediones (TZD), dipeptidyl peptidase 4 (DPP-4) inhibitors, sodium-glucose cotransporter (SGLT2) inhibitors, and a-glucosidase inhibitors.

If HBA1C is more than or equal to $9 \%$ at diagnosis initiation of combination therapy or insulin in parallel with diet and exercise is recommended. The goal is to achieve HBA $1 \mathrm{C}$ to $<6.5 \%$ by 6 months. If HBA1C is less than $9 \%$ at diagnosis monotherapy is initiated in parallel with diet and exercise. If the A1C is more than $6.5 \%$ at 3 months combination therapy is recommended with a goal to achieve A1C to less than 6.5 in 6 months [1,2].

\section{Monotherapy}

AS per ADA (American diabetes association) and EASD (European Association for the Study of Diabetes) guidelines metformin is the primary agent of choice. For monotherapy metformin is still the preferred initial pharmacological agent for type 2 diabetes unless contraindicated or not tolerated. This drug has a long-standing evidence base for efficacy and safety, is inexpensive, and has cardio protective effects. The risk for hypoglycemia is low and it causes weight loss too.

\section{Combination Therapy}

If A1C target is not achieved after 3 months of monotherapy two drug combination is advocated. Choice depends on patient and disease related factors. The factors being immediate outcome like glycemic control (HBA1C \%), effects on body weight, LDL cholesterol, HDL cholesterol and triglycerides levels. Consideration of long term clinical outcomes like all-cause mortality, cardiovascular mortality and microvascular outcomes are equally important before choosing the drugs. The most important factor in choosing the drug is their adverse effects like mild to moderate hypoglycemia, gastro intestinal intolerance, congestive heart failure, liver injury etc. Metformin can be added with other drugs. Choosing the agents among available medications requires consideration of their efficacy, mode of action, class of drugs, adverse effects and cost. If the A1C target is still not achieved after 3 months of dual therapy three drug combination is indicated. With the increasing number of available medication choices for diabetes, patients are being managed with a greater number of classes of medications in combination. Dual and triple drug combinations steadily increased from $35.0 \%$ and $6.6 \%$ in 2002 to $44.9 \%$ and $15.5 \%$ in 2013 , respectively [3].

\section{Effectiveness (HBA1c)}

Most oral diabetes agents (metformin, thiazolidinediones, sulfonylureas, and GLP1 Receptor Agonists) reduce HbA1c to a similar degree by about 1 absolute percentage point when compared with baseline values. The degree of Alc reduction needed to achieve a glycemic target for an individual should be noted while choosing addon therapy to metformin. For example, if A1c is only $0.5 \%$ above goal, one could use almost any agent and DPP4-inhibitors and SGLT2- inhibitors would remain effective options. On the other hand, if A1c is $>1 \%$ above goal, stronger agents such as GLP-1 RA, TZDs, SUs, or even insulin should be considered.

Second generation sulfonylureas (i.e. glyburide and glipizide) have comparable efficacy [4], as do various TZDs like pioglitazone and rosiglitazone [5]. When choosing from medications within the same class, other adverse effects and comorbidities should be considered. Of the second generation SUs, glipizide may be a better option than glyburide due to its shorter duration of action, particularly in patients who may be at higher risk for complications from hypoglycemia, such as the elderly [6]. There is no significant difference in Alc reduction between various DPP4 inhibitors (alogliptin, linagliptin, saxagliptin, and sitagliptin [7]).

As a new class of drugs, sodium-glucose co-transporter 2 (SGLT2) inhibitors are recommended by the American Diabetes Association (ADA) and the European Association for the Study of Diabetes (EASD) [8] which activate the proximal nephron to decrease glucose absorption, independent of insulin and therefore can be used in any stage of type 2 diabetes. Several systematic reviews have shown that SGLT2 inhibitors are effective for controlling HbA1c [9-15]. The three most representative drugs family iSGLT2 are: Dapagliflozin, canagliflozin and empagliflozin. Recently, three new SGLT2 inhibiting drugs (ipragliflozin, tofogliflozin and luseogliflozin) were introduced to clinical practice [16-18].

Dapagliflozin was the first SGLT2 inhibitor and has many published data from clinical trials. In phase 3 trials comparing placebo for 24 weeks and dapagliflozin (2.5,5 and $10 \mathrm{mg}$ once daily) used alone or added to metformin [19], pioglitazone [20] or glimepiride [21] shown reduction of $\mathrm{HbAlc}$ and fasting plasma glucose in patients with T2DM . Canagliflozin was the first of this family of drugs approved by the FDA and began its commercialization in March 2013 for use in T2DM. It is an effective drug in monotherapy and has shown durable glycemic control over a two year period when compared to glimepiride [22]. At 52 weeks, canagliflozin $300 \mathrm{mg}$ was superior to glimepiride in $\mathrm{A} 1 \mathrm{c}$ reduction, and at 2 years, the effect was maintained (A1c $-0.74 \%$ for canagliflozin $300 \mathrm{mg}$ and $-0.55 \%$ for glimepiride) [23]. Dapagliflozin, another member of the SGLT-2i class, has been compared to glipizide in a 4 year head-to-trial revealed no significant lowering of A1c [24]. The available data suggest that SGLT2i agents are more durable than SUs. Similar to the GLP-1 RA agents, the durable nature of SGLT-2is is likely multifactorial including weight loss, improvements in insulin sensitivity, improved beta cell function, and reduction of glucose toxicity $[25,26]$.

The GRADE study (Glycemic Reduction Approaches in Diabetes) will compare sitagliptin, glimepiride, glargine, and liraglutide head-tohead to establish the long-term efficacy of these medications over roughly a 5 year period. The primary outcome will be time to "failure" defined as an $\mathrm{HbAlc}>7 \%$. The trial is expected to be completed in 2020 and will give us insight into the relative long-term efficacy of these four medications.

\section{Cost}

Cost of therapy should be considered while choosing the pharmacotherapy. This will certainly help in good compliance to treatment. 


\section{Adverse effects}

Adverse effects with diabetes medications are an important consideration when choosing the right medication for patients. Of the various adverse effects, hypoglycemia is the commonest and dangerous one encountered in our daily practice. The most relevant, serious, and/or common side effects of the specific drugs are discussed below.

\section{Biguanides}

Metformin which belongs to the class of biguanides is a welltolerated drug. Though lactic acidosis is a potential adverse effect studies show that the incidence is extremely low and when it occurs, it is difficult to establish a causal relationship [12]. As per ADA and recent new FDA/EMA guideline [27,28] full dose metformin (up to 2 grams daily) can be prescribed if eGFR $\left(\mathrm{mL} / \mathrm{min}\right.$ per $\left.1.73 \mathrm{~m}^{2}\right)$ is more than 45. It should not be given when eGFR is less than 45 . If metformin is used in patients with an eGFR $<60$, renal function should be monitored more closely (i.e. every 3 months or sooner) and metformin should be discontinued if there is a rapid decline in renal function. Common adverse effect associated with metformin is GI intolerance including nausea, abdominal discomfort and diarrhoea. These effects are usually mild and wane with time [29]. GI symptoms can be minimized by starting with a low dose of metformin and increasing slowly. If a patient continues to have GI symptoms, extended release metformin can be considered. In summary, all patients with type 2 diabetes should be treated with metformin as firstline therapy. Long-term use of metformin may be associated with vitamin B12 deficiency. Therefore periodic measurement of vitamin B12 levels should also be considered in metformin-treated patients, especially in those with anemia or peripheral neuropathy along with periodic serum creatinine level.

\section{Sulfonylureas (SU)}

The 1st generation of sulfonylureas are obsolete .Second-generation agents are Glipizide, glyburide, glibenclamide, glimepiride, gliclazide, glyclopyramide. Sulphonylureas are effective anti-hyperglycaemic agents that reduce $\mathrm{HbAlC}$ by greater than $1 \%$ in monotherapy regimens. These are the main classes of drugs used in developing countries where most patients cannot afford the use of expensive newer classes of drugs. The UKPDS demonstrated the effectiveness of SU over a 10-year period. In this study, the intensive group achieved an $\mathrm{HbA1C}$ of $7 \%$ with a $25 \%$ reduction in microvascular complications and $10 \%$ reduction in any diabetes-related death. However, no beneficial effects on macrovascular complications were noted. The ADVANCE (Action in Diabetes and Vascular Disease) trial using Gliclazide has demonstrated in over 10,000 patients with type 2 diabetes, that an intensive strategy with conventional agents can achieve mean A1C levels of $6.5 \%$ safely with no increase in mortality and has no significant effect in reducing macrovascular disease, but reduces diabetic nephropathy by $20 \%$ [30].

Sulfonylureas are associated with hypoglycemia and weight gain (UKPDS). Therefore it is not recommended in elderly population where the risks of hypoglycemia is high leading to increased risk of myocardial infarction, stroke and falls etc. [31]. In patients with significant obesity and insulin resistance this group of agents are not preferred and needs using medications that are weight neutral or associated with weight loss. Major adverse effects associated with SUs make them a less attractive option as noted above. First-generation SUs, namely, tolbutamide and chlorpropamide, are not currently used and were replaced by second generation SUs, including glibenclamide, glipizide, gliclazide, and glimepiride having lesser adverse effects.

However, these medications remain efficacious and cost-effective and therefore should be considered for these reasons when appropriate.

\section{Thiazolidinediones (TZDs)}

Pioglitazone is the commonly used drug that belong to this group. TZDs are the potential 2nd and 3rd line drugs and are associated with an increased risk of oedema and congestive heart failure (CHF) [32]. Weight gain associated with TZDs may be associated with oedema in part, but is likely multifactorial, including increased fat mass [33]. Results of studies looking at cardiovascular effects of TZDs are conflicting. Results from the PROactive study showed that pioglitazone reduced non-fatal myocardial infarction and stroke in patients with type 2 diabetes mellitus (T2DM) who are at high risk for cardiovascular (CV) events [34]. Whereas the RECORD study showed an increased risk of heart failure, inconclusive results on the effects on MI, but no overall increased risk of CV morbidity and mortality with rosiglitazone [35]. These medications should be used with caution in patients with CHF or other cardiac disease. TZDs have also been associated with an increased risk of osteoporotic fracture particularly in women over $65 \mathrm{yrs}$ and appear to be more likely non-vertebral [36,37]. Given the variety of available classes of medications, some of which may have beneficial effects on weight and the cardiovascular system, the use of TZDs in patients with heart failure should be avoided. Though the risks of other serious adverse effects are low, the side effect profile of TZDs makes them a less desirable choice for oral medications. One should not use these medications in patients with osteoporosis, CV disease or CHF, or significant oedema.

\section{DPP-4 Inhibitors}

Drugs belonging to this class are vildagliptin, saxagliptin, teneligliptin, linagliptin and allogliptin. DPP4-inhibitors are some of the most well-tolerated classes of the anti-diabetic medications. Cardiovascular outcome trials with DPP4-i, including SAVOR-TIMI (saxagliptin versus placebo) [38], EXAMINE (alogliptin versus placebo) [39], and TECOS (sitagliptin versus placebo) [40] have shown no difference in CV endpoints with DPP4-i compared to placebo. However, in the SAVOR-TIMI trial, there were statistically significant higher rates of hospitalization for heart failure in the saxagliptin group compared to placebo [41]. In the EXAMINE trial, more patients experienced hospitalization for heart failure in the alogliptin group (106/2701, 3.9\%) versus placebo (89/2679, 3.3\%) [42]. These group of drugs are also associated with arthralgias [43] and the FDA has listed a post-marketing warning for joint pain associated with these medications.

\section{GLP1 RA}

Exenatide, Liraglutide and Lixisenatide are the drugs belonging to this class.Nausea is by far the most common adverse effect associated with GLP-1 RAs and it usually wanes over time [44] and can be limited by gradual dose escalation [45] except exenatide ER which is prescribed in a single dose of $2 \mathrm{mg}$ weekly. These medications should not be used in patients with gastroparesis or other causes of severe chronic nausea at baseline. GLP-1 RA are contraindicated in patients with medullary thyroid carcinoma (MTC), family history of thyroid carcinoma, or patients with Multiple Endocrine Neoplasia 2 (MEN2) 
due to an increase in thyroid C-cell tumors seen in rodent studies. Similar results have not been seen in human studies and may be due to species-specific differences in GLP-1 receptor expression in the thyroid [46]. Exenatide is contraindicated in patients with creatinine clearance $<30 \mathrm{~mL} / \mathrm{min}$. The remaining GLP1-RA have not been well-studied in patients with eGFR $<30$ and are not recommended in patients with stage $4 \mathrm{CKD}$ with eGFR $<30 \mathrm{~mL} / \mathrm{min}$ per $1.73 \mathrm{~m}^{2}$. Lixisenatide (trade name Lyxumia in Europe and Adlyxin in U.S.) is a once-daily injectable GLP-1 receptor agonist for the treatment of type 2 diabetes mellitus. Use with insulin or sulfonylurea may cause hypoglycemia. Dulaglutide Indicated as once-weekly SC injection as an adjunct to diet and exercise to improve glycemic control in adults with type 2 diabetes mellitus.Initial dose is $0.75 \mathrm{mg} \mathrm{SC}$ once weekly and may be increased to $1.5 \mathrm{mg}$ once weekly for additional glycemic control. No dose adjustment is required in renal impairment. However it is not recommended as first-line therapy for patients inadequately controlled on diet and exercise.

\section{Meglitinide Analogues}

Meglitinide analogues (Repaglinide, Nateglinide) are a class of oral antidiabetic agents that increase insulin secretion in the pancreas. Two analogues are currently available for clinical use: repaglinide and nateglinide. In the eleven studies comparing meglitinides to placebo both repaglinide and nateglinide resulted in a reductions in glycosylated haemoglobin $(0.1 \%$ to $2.1 \%$ reduction in $\mathrm{HbAlc}$ for repaglinide; $0.2 \%$ to $0.6 \%$ for nateglinide) [47]. Weight gain and hypoglycaemia are the potential adverse effects though it is less than for those on sulfonylureas. Meglitinides may offer an alternative oral hypoglycaemic agent of similar potency to metformin, and may be indicated where side effects of metformin are intolerable or where metformin is contraindicated. However, there is no evidence available to indicate what effect meglitinides will have on important longterm outcomes, particularly mortality. Since there is flexibility in meal time dosing and irregular meal patterns it is a preferred 'Ramzan Drug'.

\section{Alpha Glucosidase Inhibitors}

Alpha glucosidase inhibitors (acarbose, miglitol, voglibose) are widely used in the treatment of patients with type 2 diabetes. AGIs delay the absorption of carbohydrates from the small intestine and thus have a lowering effect on postprandial blood glucose and insulin levels. The disadvantages are abdominal distension and not to be prescribed in inflammatory bowel disease, such as ulcerative colitis or crohn's disease and intestinal obstruction.

\section{SGLT-2 Inhibitors}

These are a class of medications that inhibit reabsorption of glucose in the kidney and therefore lower blood glucose. Apart from glycemic control, gliflozins have been shown to provide significant cardiovascular benefit in T2DM patients. The drugs belonging to this class are Dapagliflozin, canagliflozin, empagliflozin and many more are under the pipeline.SGLT2-i are associated with an increased risk of genital mycotic infections [48-50]. FDA issued a warning after 19 reported cases of severe urosepsis and pyelonephritis. A more serious, although rare, complication associated with SGLT2-i is ketoacidosis. Blood pressure reduction and dehydration can occur due to osmotic diuresis with SGLT2-i [51]. While this could potentially be a benefit for some patients, one should use these medications with caution in patients who may be at risk for hypotension. In patients on loop diuretics, consider a decrease in dosage or discontinuation. Lastly, there has also been some concern about malignancy associated with the use of SGLT2-inhibitors. Dapagliflozin has been associated with an increased risk of bladder cancer and is therefore contraindicated in patients with active bladder cancer.

\section{Patient's preference/compliance}

Unfortunately the proportion of patients reaching Alc goals has remained around 50\% during the last decade despite the availability of new medications [52]. This disparity is probably due to patient compliance and adherence. Poor patient compliance is multifactorial. A recent review article by Polonsky and Henry proposed that the reasons come down to six factors [53]. Those are perceived efficacy, episodes of hypoglycaemia ,treatment complexity, medication cost and trust on physician. While many of these factors are self-explanatory, one must keep in mind that perceived efficacy might be different between patient and provider. While a provider may focus on A1c reduction, a patient may prioritize weight. If a patient perceives a medication as more effective in whatever area they deem most meaningful, they are more likely to continue the drug. Finally, treatment complexity deserves special attention as taking a pill once a day results in compliance rates of roughly $80 \%$, while that number falls to less than $50 \%$ for three times daily $[54,55]$. Therefore patients preference is of paramount importance in choosing the drugs [56-63].

\section{Intermediate outcomes: overview of weight results}

The effects on lipid levels varied across medication type, but most were small to moderate around 5 to $10 \mathrm{mg} / \mathrm{dL}$ in low-density lipoproteins (LDL), 10 to $30 \mathrm{mg} / \mathrm{dl}$ in triglycerides (TG), and 3 to 5 $\mathrm{mg} / \mathrm{dl}$ in high-density lipoproteins (HDL). Metformin had favorable effects on all the lipid classes. Decisions regarding medications that may adversely affect lipids are important because of the importance of cardiovascular disease risk reduction in patients with diabetes.

\section{Cardio-protectiveness}

Review of various trials have concluded that favourable glycaemic efficacy does not necessarily translate to favourable cardiovascular outcomes. Cardiovascular safety needs to be prioritized over glucocentricity. This paradigm shift from glucocentricity to cardioprotectiveness poses a challenge to the practitioners to balance between the benefit of glycaemic control and the inherent risk in glucose lowering medications. As the diabetic patients are at high risk for cardiovascular morbidity and mortality the knowledge of cardioprotective effects of diabetic drugs is important for the clinicians dealing with this condition and translating it in patient care. Recommendation Based on current evidence, metformin should remain the first line drug of choice in $\mathrm{T} 2 \mathrm{DM}$, being the most extensively studied and demonstrating excellent cardiovascular safety even with long term use. Although evidence for the cardiovascular safety of sulfonylureas are inconsistent, the first-generation agents are probably associated with net harm and should be avoided. Newer generation sulfonylureas have a comparatively better cardiovascular profile, but weight gain remains a problem. Targeting mainly postprandial hyperglycaemia, alpha-glucosidase inhibitors favourably affect several cardiovascular risk factors, such as obesity, hypertension and high glycaemic variability with little to no risk for hypoglycaemia. The Study To Prevent Non-insulin-dependent Diabetes Mellitus (STOP-NIDDM) trial an international multicenter placebo-controlled trial has demonstrated that the use of Acarbose helps in the prevention 
of cardiovascular disease in subjects with IGT mpaired glucose tolerance and T2DM.

Among the TZDs pioglitazone may have beneficial cardiovascular effects but contraindicated in heart failure. The incretin-based drugs have been at the forefront in the era of cardiovascular safety trials and have been extensively studied. Current evidence suggests that the gliptins have neutral cardiovascular effect, but may increase risk of heart failure, particularly saxagliptin. Among the GLP-1 agonists, liraglutide may have beneficial effects on cardiovascular outcomes, but this requires further validation. Similarly, the SGLT-2 inhibitors have shown promising results with empagliflozin and may potentially confer cardiovascular benefits, although additional data is needed to substantiate this. Several large ongoing randomized trials whose results are expected in the coming years. This will definitely guide the clinicians to optimize the treatment for their diabetic patients (Table 1) [64-67].

\begin{tabular}{|c|c|c|c|c|c|c|c|}
\hline Parameters & $\begin{array}{l}\text { Biguanides- } \\
\text { Metformin }\end{array}$ & Sulfonylureas & Thiazolidinediones & $\begin{array}{l}\text { DPP4 } \\
\text { inhibitors }\end{array}$ & SGLT2 inhibitors & $\begin{array}{l}\text { GLP1 } \\
\text { receptor } \\
\text { agonist }\end{array}$ & $\begin{array}{l}\text { Alpha } \\
\text { glucosidase } \\
\text { inhibitors }\end{array}$ \\
\hline $\begin{array}{l}\text { Efficacy- } \\
\text { Reduction of } \\
\text { A1C }\end{array}$ & $\begin{array}{l}\text { High } \\
1-2 \%\end{array}$ & $\begin{array}{l}\text { High } \\
1-2 \%\end{array}$ & $\begin{array}{l}\text { High } \\
0.5-1.4 \%\end{array}$ & $\begin{array}{l}\text { Intermediate } \\
0.5-0.8 \%\end{array}$ & High & $\begin{array}{l}\text { High } \\
0.5-1.5 \%\end{array}$ & Intermediate \\
\hline $\begin{array}{l}\text { Risk of } \\
\text { Hypoglycemia }\end{array}$ & Low & Moderate & Low & Low & Low & Low & Low \\
\hline Adverse Effects & GI Intolerance & Hypoglycemia & Edema, Heart Failure & Rare & Genito urinary infection & Rare & $\begin{array}{l}\text { Abdominal } \\
\text { distension }\end{array}$ \\
\hline Weight gain & Loss & Gain & Gain & Neutral & Loss & Loss & Loss \\
\hline Cost & Low & Low & Low & High & High & High & Low \\
\hline $\begin{array}{l}\text { Cardio- } \\
\text { protecveness }\end{array}$ & $\begin{array}{l}\mathrm{CV} \\
\text { Protective }\end{array}$ & $\begin{array}{l}1^{\text {st }} \text { generation } \\
\text { harmful } \\
\text { Inconsistent }\end{array}$ & Inconsistent & $\begin{array}{l}\text { No difference } \\
\text { in } \quad \mathrm{CV} \\
\text { Endpoints }\end{array}$ & $\mathrm{CV}$ protective & CV Protective & $\begin{array}{l}\mathrm{CV} \\
\text { Protective }\end{array}$ \\
\hline
\end{tabular}

Table 1: Guides to choose the best oral diabetic agent depending on the criteria.

\section{Conclusion}

The ultimate goal is to achieve glycemic control with minimal side effects. Achieving this goal for each individual patient is of paraamount importance rather that establishing a universally accepted algorithm. Upon diagnosis, patients should be educated on appropriate lifestyle modifications primarily diet and activity. Metformin is the first line medication unless contra indicated. The advantages and disadvantages of each class of agents help the practitioners to choose the best options when combination therapy is needed. The factors considered are efficacy (Alc reduction), risk of hypoglycaemia , effect on weight and other adverse effects, cost, availability, comorbidities and frequency of administration. Patient's preference will definitely improve the adherence and compliance to drugs. Therefore a patientcentered approach is of equal importance while choosing the pharmacological agents.

\section{References}

1. Standards of medical care in diabetes-2016: summary of revisions. Diabetes Care 39 (Suppl 1): S4-S5.

2. James JC, Andrew SR, Charles FS Jr, Annie N (2016) PA-C diagnosis and management of diabetes: synopsis of the 2016; American Diabetes Association standards of medical care in diabetes. Ann Intern Med 164: $542-552$.

3. Seung-Hyun K, Dae-Jung K, Jong-Heon P, Cheol-Young P, Chang-Hee J, et al. (2016) Trends of antidiabetic drug use in adult type 2 diabetes in Korea in 2002-2013: Nationwide population-based cohort study. Medicine 95: 27.

4. Birkeland Kl, Furuseth K, Melander A, Mowinckel P, Vaaler S (1994) Long-term randomized placebo-controlled double-blind therapeutic comparison of glipizide and glyburide: Glycemic control and insulin secretion during 15 months. Diabetes Care pp: 45-49.

5. Goldberg RB, Kendall DM, Deeg MA, Buse JB, Zagar AJ, et al. (2005) A comparison of lipid and glycemic effects of pioglitazone and rosiglitazone in patients with type 2 diabetes and dyslipidemia. Diabetes Care 28: 1547-1554.

6. By the American Geriatrics Society Beers Criteria Update Expert Panel (2015) American Geriatrics Society 2015 Updated Beers Criteria for Potentially Inappropriate Medication Use in Older Adults. J Am Geriatr Soc 63: 2227-2246.

7. Craddy P, Palin HJ, Johnson KI (2014) Comparative effectiveness of dipeptidylpeptidase- 4 inhibitors in type 2 diabetes: a systematic review and mixed treatment comparison. Diabetes Ther 5: 1-41.

8. Inzucchi SE, Bergenstal RM, Buse JB (2015) Management of hyperglycemia in type 2 diabetes, 2015: a patient-centered approach: update to a position statement of the American Diabetes Association and the European Association for the Study of Diabetes. Diabetes Care 38: 140

9. Vasilakou D, Karagiannis T, Athanasiadou E (2013) Sodium-glucose cotransporter 2 inhibitors for type 2 diabetesa systematic review and meta-analysis. Ann Intern Med 159: 262-274.

10. Liakos A, Karagiannis T, Athanasiadou E (2014) Efficacy and safety of empagliflozin for type 2 diabetes: a systematic review and meta-analysis. Diabetes Obes Metab 16: 984-93.

11. Goring S, Hawkins N, Wygant G, Townsend R, Wood I, et al. (2014) Dapagliflozin compared with other oral anti-diabetes treatments when added to metformin monotherapy: a systematic review and network meta-analysis. Diabetes Obes Metab 16: 433-42.

12. Mearns ES, Saulsberry WJ, White CM, Lemieux S, Sihabout A, et al. (2015) Efficacy and safety of antihyperglycaemic drug regimens added to metformin and sulphonylurea therapy in type 2 diabetes: a network metaanalysis. Diabet Med 32: 1530-1540 
13. Monami M, Nardini C, Mannucci E (2014) Efficacy and safety of sodium glucose co-transport-2 inhibitors in type 2 diabetes: a meta-analysis of randomized clinical trials. Diabetes Obes Metab 16: 457-466.

14. Yang T, Lu M, Ma L, Zhou Y, Cui Y (2015) Efficacy and tolerability of canagliflozin as add-on to metformin in the treatment of type 2 diabetes mellitus: a meta-analysis. Eur J Clin Pharmacol 71: 1325-1332.

15. Clar C, Gill JA, Court R, Waugh N (2012) Systematic review of SGLT2 receptor inhibitors in dual or triple therapy in type 2 diabetes. BMJ Open 2: e001007.

16. Kashiwagi A, Kazuta K, Yoshida S (2014) Randomized, placebocontrolled, double-blind glycemic control trial of novel sodiumdependent glucose cotransporter 2 inhibitor ipragliflozin in Japanese patients with type 2 diabetes mellitus. J Diabetes Investig 5: 382-391.

17. Kaku K, Watada H, Iwamoto Y (2014) Efficacy and safety of monotherapy with the novel sodium/glucose cotransporter-2 inhibitor tofogliflozin in Japanese patients with type 2 diabetes mellitus: a combined Phase 2 and 3 randomized, placebo-controlled, double-blind, parallel-group comparative study. Cardiovasc Diabetol 13: 65.

18. Seino Y, Inagaki N, Haneda M, Kaku K, Sasaki T, et al. (2015) Efficacy and safety of luseogliflozin added to various oral antidiabetic drugs in Japanese patients with type 2 diabetes mellitus. J Diabetes Investig 6: 443-453

19. Bailey CJ, Gross JL, Pieters A, Bastien A, List JF (2010) Effect of dapagliflozin in patients with type 2 diabetes who have inadequate glycaemic control with metformin: a randomised, double-blind, placebocontrolled trial. Lancet 375: 2223-2233.

20. Rosenstock J, Vico M, Wei L, Salsali A, List JF (2012) Effects of dapagliflozin, an SGLT2 inhibitor, on $\mathrm{HbA}(1 \mathrm{c})$, body weight, and hypoglycemia risk in patients with type 2 diabetes inadequately controlled on pioglitazone monotherapy. Diabetes Care 35: 1473-1478.

21. Strojek K, Yoon KH, Hruba V, Elze M, Langkilde AM, et al. (2011) Effect of dapagliflozin in patients with type 2 diabetes who have inadequate glycaemic control with glimepiride: a randomized, 24-week, doubleblind, placebo-controlled trial. Diabetes Obes Metab 13: 928-938.

22. Leiter LA, Yoon KH, Arias P, Langslet G, Xie J, et al. (2015) Canagliflozin provides durable glycemic improvements and body weight reduction over 104 weeks versus glimepiride in patients with type 2 diabetes on metformin: a randomized, double-blind, phase 3 study. Diabetes Care 38: 355-364.

23. Schernthaner G, Gross JL, Rosenstock J, Guarisco M, Fu M, et al. (2013) Canagliflozin compared with sitagliptin for patients with type 2 diabetes who do not have adequate glycemic control with metformin plus sulfonylurea: a 52-week randomized trial. Diabetes Care 36: 2508-2515.

24. Del Prato S, Nauck M, Durán-Garcia S, Maffei L, Rohwedder K, et al. (2015) Long-term glycaemic response and tolerability of dapagliflozin versus a sulphonylurea as add-on therapy to metformin in patients with type 2 diabetes: 4-year data.Diabetes Obes Metab 17: 581-590.

25. Merovci A, Mari A, Solis-Herrera C, Xiong J, Daniele G, et al. (2015) Dapagliflozin lowers plasma glucose concentration and improves beta-cell function. J Clin Endocrinol Metab 100: 1927-1932.

26. Ele Ferrannini, Elza Muscelli, Silvia Frascerra, Simona Baldi, Andrea Mari, et al. (2014) Metabolic response to sodium-glucose cotransporter 2 inhibition in type 2 diabetic patients. J Clin Invest 124: 499-508.

27. Inzucchi SE, Lipska KJ, Mayo H, Bailey CJ, McGuire DK (2014) Metformin in patients with type 2 diabetes and kidney disease: a systematic review. JAMA 312: 2668-2675.

28. Nathan DM1, Buse JB, Davidson MB, Ferrannini E, Holman RR, et al. (2009) Medical management of hyperglycemia in type 2 diabetes: a consensus algorithm for the initiation and adjustment of therapy: a consensus statement of the American Diabetes Association and the European Association for the Study of Diabetes. Diabetes Care 32: 193-203.

29. Bailey CJ,Turner RC (1996) Metformin. N Engl J Med 334: 574-579.

30. Simon R Heller (2009) A Summary of the ADVANCE Trial Diabetes Care 32: S357-S361.
31. Zammitt NN, Frier BM (2005) Hypoglycemia in type 2 diabetes: pathophysiology, frequency, and effects of different treatment modalities. Diabetes Care 28: 2948-2961.

32. Nesto RW, Bell D, Bonow RO, Fonseca V, Grundy SM, et al. (2003) Thiazolidinedione use, fluid retention, and congestive heart failure: a consensus statement from the American Heart Association and American Diabetes Association 108: 2941-2948.

33. Basu A, Jensen MD, McCann F, Mukhopadhyay D, Joyner MJ, et al. (2006) Effects of pioglitazone versus glipizide on body fat distribution, body water content, and hemodynamics in type 2 diabetes. Diabetes Care 29: 510-514.

34. Dormandy JA, Charbonnel B, Eckland DJ, Erdmann E, Massi-Benedetti $\mathrm{M}$, et al. (2005) Secondary prevention of macrovascular events in patients with type 2 diabetes in the PROactive Study (PROspective pioglitAzone Clinical Trial In macroVascular Events): a randomised controlled trial. Lancet 366: 1279-1289.

35. Home PD, Pocock SJ, Beck-Nielsen H, Curtis PS, Gomis R, et al. (2009) Rosiglitazone evaluated for cardiovascular outcomes in oral agent combination therapy for type 2 diabetes (RECORD): a multicentre, randomised, open-label trial. Lancet 373: 2125-2135.

36. Meier C, Kraenzlin ME, Bodmer M, Jick SS, Jick H, Meier CR (2008) Use of thiazolidinediones and fracture risk. Arch Intern Med 168: 820-825.

37. Habib ZA, Havstad SL, Wells K, Divine G, Pladevall M, Williams LK, et al. (2010) Thiazolidinedione use and the longitudinal risk of fractures in patients with type 2 diabetes mellitus. J Clin Endocrinol Metab 95: 592-600.

38. Scirica BM, Bhatt DL, Braunwald E, Steg PG, Davidson J, et al. (2013) Saxagliptin and cardiovascular outcomes in patients with type 2 diabetes mellitus. N Engl J Med 369: 1317-1326.

39. White WB, Christopher PC, Simon RH, Steven EN, Richard MB, et al. (2013) Alogliptin after acute coronary syndrome in patients with type 2 diabetes.N Engl J Med 369: 1327-1335.

40. Green JB, Bethel MA, Armstrong PW, Buse JB, Engel SS, et al. (2015) Effect of Sitagliptin on Cardiovascular Outcomes in Type 2 Diabetes. N Engl J Med 373: 232-242.

41. Scirica BM (2013) Saxagliptin and cardiovascular outcomes in patients with type 2 diabetes mellitus. N Engl J Med 369: 1317-1326.

42. White WB (2013) Alogliptin after acute coronary syndrome in patients with type 2 diabetes.N Engl J Med 369: 1327-1335.

43. Chaicha-Brom T, Yasmeen T (2013) DPP-IV inhibitor-associated arthralgias. Endocr Pract 19: 377.

44. Shyangdan DS (2011) Glucagon-like peptide analogues for type 2 diabetes mellitus.Cochrane Database Syst Rev 10: 6423.

45. Fineman MS (2004) Effectiveness of progressive dose-escalation of exenatide (exendin-4) in reducing dose-limiting side effects in subjects with type 2 diabetes. Diabetes Metab Res Rev 20: 411-417.

46. Knudsen L (2010) Glucagon-like Peptide-1 receptor agonists activate rodent thyroid C-cells causing calcitonin release and C-cell proliferation. Endocrinology 151: 1473-1486.

47. Black C, Donnelly P, McIntyre L, Royle P (2007) Meglitinide analogues for type 2 diabetes mellitus. Cochrane Database of Systematic Reviews.

48. Clar C (2012) Systematic review of SGLT2 receptor inhibitors in dual or triple therapy in type 2 diabetes. BMJ Open 2: e001007.

49. Musso G (2012) A novel approach to control hyperglycemia in type 2 diabetes: sodium glucose co-transport (SGLT) inhibitors: systematic review and meta-analysis of randomized trials. Ann Med 44: 375-393.

50. Zinman B (2015) Empagliflozin, Cardiovascular Outcomes, and Mortality in Type 2 Diabetes. N Engl J Med 373: 2117-2128.

51. Weir MR (2014) Effect of canagliflozin on blood pressure and adverse events related to osmotic diuresis and reduced intravascular volume in patients with type 2 diabetes mellitus. J Clin Hypertens 16: 875-882.

52. Ali MK (2013) Achievement of goals in U.S. diabetes care, 1999-2010. N Engl J Med 368: 1613-1624. 
Citation: Mohanty B (2018) Choosing the Best Oral Diabetic Agents in T2 Diabetes Mellitus-Physicians Challenge. J Diabetes Metab 9: 797. doi: $10.4172 / 2155-6156.1000797$

Page 7 of 7

53. Polonsky WH, Henry RR (2016) Poor medication adherence in type 2 diabetes: recognizing the scope of the problem and its key contributors. Patient Prefer Adherence 10: 1299-1307.

54. Coleman CL (2012) Dosing frequency and medication adherence in chronic disease. J Manag Care Pharm 18: 527-539.

55. Saini SD (2009) Effect of medication dosing frequency on adherence in chronic diseases. Am J Manag Care 15: 22-33.

56. Wright A (1999)United Kingdom Prospective Diabetes Study 24: a 6-year, randomized, controlled trial comparing sulfonylurea, insulin, and metformin therapy in patients with newly diagnosed type 2 diabetes that could not be controlled with diet therapy. United Kingdom Prospective Diabetes Study Group. Ann Intern Med 128: 165-175.

57. Hermann LS (1994) Therapeutic comparison of metformin and sulfonylurea, alone and in various combinations. A double-blind controlled study. Diabetes Care 17: 1100-1109.

58. Knowler WC (2002) Reduction in the incidence of type 2 diabetes with lifestyle intervention or metformin. N Engl J Med 346: 393-403.

59. Diabetes Prevention Program Research (2009) 10-year follow-up of diabetes incidence and weight loss in the Diabetes Prevention Program Outcomes Study. Lancet 374: 1677-1686.

60. Clar C (2012) Systematic review of SGLT2 receptor inhibitors in dual or triple therapy in type 2 diabetes. BMJ Open 2.
61. Shyangdan DS (2011) Glucagon-like peptide analogues for type 2 diabetes mellitus.Cochrane Database Syst Rev 10: 6423.

62. Vilsboll T (2012) Effects of glucagon-like peptide-1 receptor agonists on weight loss: systematic review and meta-analyses of randomised controlled trials. BMJ 344: 7771 .

63. Davies MJ (2009) Efficacy of Liraglutide for Weight Loss Among Patients With Type 2 Diabetes: The SCALE Diabetes Randomized Clinical Trial. JAMA 314: 687-699.

64. Nissen SE, Wolski K (2007) Effect of rosiglitazone on the risk of myocardial infarction and death from cardiovascular causes. $\mathrm{N}$ Engl J Med 356: 2457-2471.

65. Mohanty B (2017) Lower Cardiovascular Risk with Diabetic Drugs: A Paradigm Shift from Glucocentricity to Cardio Protectiveness. Diabetes Case Rep 2: 123.

66. Clinical trials Gov (2015) Multicentre trial to evaluate the effects of Dapagliflozin on the incidence of cardiovascular events.

67. Food and Drug Administration (2008) Guidance for Industry: Diabetes mellitus-Evaluating cardiovascular risk in new antidiabetic therapies to treat type 2 diabetes. 